\title{
Effects of hemin, a heme oxygenase-1 inducer in L-arginine-induced acute pancreatitis and associated lung injury in adult male albino rats
}

\author{
Aziz NM, Kamel MY, RifaAi RA \\ Departments of Physiology, Pharmacology and Histology, Faculty of Medicine, Minia University, Minia, Egypt \\ Email:emadmax71@yahoo.com
}

\begin{abstract}
Objective. The aim of the current study was to assess the protective outcome of hemin, a heme oxygenase-1 (HO-1) inducer on L-arginine-induced acute pancreatitis in rats. Acute pancreatitis (AP) is considered to be a critical inflammatory disorder with a major impact on the patient health. Various theories have been recommended regarding the pathophysiology of AP and associated pulmonary complications.

Methods. Twenty-four adult male albino rats were randomly divided into four groups: control group, acute pancreatitis (AP), hemin pre-treated AP group, and hemin post-treated AP group.

Results. Administration of hemin before induction of AP significantly attenuated the L-arginine-induced pancreatitis and associated pulmonary complications characterized by the increasing serum levels of amylase, lipase, tumor necrosis factor- $\alpha$, nitric oxide, and histo-architectural changes in pancreas and lungs as compared to control group. Additionally, pre-treatment with hemin significantly compensated the deficits in total antioxidant capacities and lowered the elevated malondialdehyde levels observed with AP. On the other hand, post-hemin administration did not show any protection against L-arginine-induced AP.

Conclusions. The current study indicates that the induction of HO-1 by hemin pre-treatment significantly ameliorated the L-arginine-induced pancreatitis and associated pulmonary complications may be due to its anti-inflammatory and antioxidant properties.
\end{abstract}

Key words: acute pancreatitis, heme oxygenase-1, hemin, malondialdehyde, total antioxidant capacities

Acute pancreatitis (AP) is an inflammatory disease with wide clinical variation, ranging from a mild to a severe necrotizing inflammation (Akyazi et al. 2013). Most cases are resulting from the gallstones or excess alcohol utilization. Irrespective of the reason, activation of digestive enzymes inside pancreatic acinar cells is the fundamental initiating event. Pancreatic damage then leads to the localized and in turn systemic inflammatory response (Kambhampati et al. 2014).

The oxygen free radicals and crucial pro-inflammatory cytokines, such as tumor necrosis factor- $\alpha$
(TNF- $\alpha$ ), interleukin-1 (IL-1 $\beta$ ) and interleukin-6 (IL-6), which play an important role in AP and other systemic inflammatory conditions, have been suggested to be responsible for the local tissue damage and various organ failures (Yenicerioglu et al. 2013). Acute lung injury (ALI) seems to be the most important cause of death in patients with AP. The fundamental molecular mechanisms behind the increase of lung injury are complex and not completely understood, which may elucidate the lack of specific pharmacologic therapies (Akbarshahi et al. 2014).

Corresponding author: Neven Makram Aziz, Assistant Professor, Department of Physiology, Faculty of Medicine, Minia University, 61111, Minia, Egypt; phone: +2 0122256894; fax: +2 086 2324414; e-mail: emadmax71@yahoo.com. 
The inducible heme oxygenase (HO) isozyme, HO-1, which exhibits low basal expression levels in most cells and tissues, is up-regulated by various stimulants, such as oxidative stress, inflammation, and endotoxins. HO-1 has multiple biological effects on antioxidant, anti-inflammatory, and immune regulatory functions through the period of cellular stress. Induction of HO-1 in islets of Langerhans results in the protection from the detrimental effect that is mediated by cytokines (Lee et al. 2011). Up-regulation of HO-1 or management with its downstream effectors and heme degradation products, biliverdin and carbon monoxide have protective effects in different rodent models of AP. HO-1 over-expressing macrophages protect against AP (Kambhampati et al. 2014).

Therefore, the current study was conducted to assess the outcome of hemin, HO-1 inducer on the experimental AP in rats. By designing an experimental study with a pre- and post-hemin treatment, we focused on the preventive and curative effects of hemin, because the numerous and diverse mechanisms of action of hemin. Here comes the question "Which is the more potent pre- or post-treatment of hemin in AP management?" To answer this question, different biochemical parameters, oxidant-antioxidant status, histological changes, and the expression of HO-1 were measured in order to reveal that which of them is the most potent and the possible protective mechanisms acting against the damage.

\section{Materials and Methods}

Animals. Adult male albino rats (Sprague-Dawley strain) 4-month old and weighing 200-250 g were used in the present study. Rats were obtained from the National Research Center, Cairo, Egypt. They were left free in their cages with normal dark:light cycle for two weeks of acclimatization before starting the experiment. They were supplied with tap water and normal diet (El-Nile Company, Egypt). All the experimental events were in accordance with our institutional guidelines. The ethics of the protocol were established by The Laboratory Animals' Maintenance and Usage Committee of Faculty of Medicine, Minia University. The rats were randomly divided into the following four groups (6 rats in each): 1) Control group, each rat received $0.5 \mathrm{ml}$ of hemin vehicle intraperitoneal (i.p.).; 2) acute pancreatitis (AP) group, each rat received two i.p. injections of $\mathrm{L}$-arginine ( $2.5 \mathrm{~g} / \mathrm{kg}, 1 \mathrm{~h}$ apart) and vehicle; 3 ) hemin pre-treated AP group, each rat received i.p. $30 \mathrm{mg} / \mathrm{kg}$ of the hemin, $12 \mathrm{~h}$ before the first injection of L-arginine; 4) hemin post-treated AP group, each rat received i.p.
$30 \mathrm{mg} / \mathrm{kg}$ of the hemin, $12 \mathrm{~h}$ after the last injection of L-arginine.

Drug protocol. L-arginine, powder (Sigma, UT, USA) was prepared as a solution by dissolving in $0.9 \%$ saline to a ultimate concentration of $500 \mathrm{mg} / \mathrm{ml}$ and the $\mathrm{pH}$ was adjusted to 7 with $5 \mathrm{~N} \mathrm{HCl}$. Hemin (Sigma, UT, USA) was freshly dissolved in $0.1 \mathrm{~mol} / 1$ $\mathrm{NaOH}$, with adjusted $\mathrm{pH}$ at 7.4 by $0.1 \mathrm{~mol} / \mathrm{HCL}$, and diluting with saline to required volume (vehicle). Hemin dose and timing was selected on the foundation of a previous study of Habtezion et al. (2011) who reported that $12 \mathrm{~h}$ following the panhematin (a watersoluble intravenous formulation of hemin) injection was the best time of increasing $\mathrm{HO}$ expression.

L-arginine-induced pancreatitis model. Acute pancreatitis was induced in three groups of rats $(n=6)$ by two i.p. injections of L-arginine $(2.5 \mathrm{~g} / \mathrm{kg}, 1 \mathrm{~h}$ apart) (Biradar and Veeresh 2013).

Biochemical analysis. Immediately $24 \mathrm{~h}$ after AP induction, animals were sacrificed by decapitation under brief halothane anesthesia. Blood samples were collected and centrifuged for $10 \mathrm{~min}$ at $5000 \times \mathrm{g}$. The obtained clear sera were stored at $-80^{\circ} \mathrm{C}$ until used for enzymatic colorimetric estimation of serum amylase, lipase (Bio-Assay, USA) and nitric oxide (NO) (Biodiagnostic, Egypt) and the serum TNF-a by enzymelinked immunosorbent assay (ELISA) using rat's TNF- $a$ ELISA kit (Lab Vision Corporation, USA).

Analysis of pancreatic and lung homogenates. Subsequent to animals sacrificing, pancreatic and lung tissues were removed. One part of the pancreas and lung tissues of each animal was used for homogenization, while the remaining portion was embedded into $10 \%$ formalin for histopathological examination. The pancreatic and lung tissues kept at $-80^{\circ} \mathrm{C}$ and subsequently homogenized in cold potassium phosphate buffer $(0.05 \mathrm{M}, \mathrm{pH} 7.4)$. The proportion of tissue weight to homogenization buffer was 1:10. The homogenates were centrifuged at $5000 \mathrm{rpm}$ for $10 \mathrm{~min}$ at $4^{\circ} \mathrm{C}$. The resulting supernatant was used for determination of malondialdehyde (MDA) and total antioxidant capacities (TAC) using colorimetric assay kit according to the recommendations of the manufacturer (Bio-diagnostic, Egypt).

Histological examination. The pancreas and lungs were dissected and fixed in $10 \%$ formalin solution. Specimens were dehydrated, processed to obtain paraffin blocks, cut into $6-7-\mu \mathrm{m}$ sections, and stained using hematoxylin and eosin (H\&E) (Sigma-Aldrich, Egypt). For histological evaluation of the pancreatic tissue damage, some changes, such as edema, hemorrhage, leukocyte infiltration, acinar degeneration were scored by grading as described by Gulcubuk et 
al. (2005). In addition, semi-quantitative evaluation of lung inflammation such as peribronchiolar inflammation plus alveolar wall thickening were evaluated in the stained sections of all groups as described before (Charavaryamath et al. 2008).

For immunohistochemical finding of HO-1, paraffin sections were deparaffinized in xylene, hydrated and then embedded in $3 \% \mathrm{H}_{2} \mathrm{O}_{2}$ for $10 \mathrm{~min}$. The sections were treated with $2 \%$ trypsin for $10 \mathrm{~min}$. Nondefinite protein binding was blocked with normal goat serum provided in the Vectastain Universal Elite $\mathrm{ABC}$ kit (Vector Laboratories). The sections were incubated for $2.5 \mathrm{~h}$ with anti-HO-1 rabbit polyclonal antibody (Stressgen Biotechnologies, Canada) and washed in buffer, they were incubated with diluted the secondary antibody and $\mathrm{ABC}$ reagent (Vectastain Universal Elite, Vector Laboratories, USA) for $30 \mathrm{~min}$, consecutively. Finally, the sections were in-

Table 1

Effect of pre- and post-hemin treatment on the serum levels of the pancreatic markers in L-arginine induced acute pancreatitis

\begin{tabular}{|c|c|c|}
\hline Group $\quad$ Parameters & $\begin{array}{c}\text { Amylase level } \\
(\mathrm{U} / \mathrm{l})\end{array}$ & $\begin{array}{c}\text { Lipase level } \\
(\mathrm{U} / \mathrm{l})\end{array}$ \\
\hline Control & $12.40 \pm 0.67$ & $500 \pm 1.84$ \\
\hline AP & $41.40 \pm 0.60^{\mathrm{a}}$ & $1425 \pm 2.42^{\mathrm{a}}$ \\
\hline Hemin pre-treated AP & $14.20 \pm 0.58^{\mathrm{b}}$ & $507 \pm 2.71^{b}$ \\
\hline Hemin post-treated AP & $39.00 \pm 0.71^{\mathrm{ac}}$ & $1423 \pm 2.15^{\text {ac }}$ \\
\hline
\end{tabular}

Data are expressed as mean \pm S.E.M. of 6 rats in each group. ${ }^{\mathrm{a}} \mathrm{p}<0.05$ vs. control group; ${ }^{b} \mathrm{p}<0.05$ vs. AP group; ${ }^{\mathrm{c}} \mathrm{p}<0.05$ vs. hemin pre-treated AP group. AP - acute pancreatitis cubated with 3,3'-diaminobenzidine tetrahydrochloride (DAKO, Denmark) and counterstained with hematoxylin (Cote et al. 1993). The negative control included sections incubated in the lack of the primary antibody, whereas the spleen was the positive control.

Image capture. Selected images were digitally captured in bright-field mode using a hardware consisting of a high-resolution color digital camera (U.TV0.5XC-3) mounted on an Olympus microscope (Olympus, Japan), connected to a computer and analyzed using Adobe Photoshop.

Statistical analysis. Data were presented as means \pm standard errors of the mean (S.E.M.). Statistical analysis was performed using Graph pad Prism 5 software and significant variation between groups was made by one-way ANOVA followed by TukeyKramer post hoc test for multiple comparisons with a value of $\mathrm{p}<0.05$ considered statistically significant.

\section{Results}

Effect of pre- and post-hemin treatment on the serum levels of amylase, lipase, NO and TNF- $\alpha$ in $\mathrm{L}$-arginine-induced acute pancreatitis. Pancreatic injury markers (serum amylase and lipase), serum NO and TNF-a levels were significantly higher in AP group than in the control group. However, pretreatment with hemin significantly decreased the serum amylase, lipase, NO and TNF- $\alpha$ levels as compared to AP rats. On the other hand, post-treatment with hemin failed to produce any significant change in the serum levels of amylase, lipase, NO, and TNF- $\alpha$ as compared to AP rats (Table 1 and Figure 1, respectively).
Figure 1. TNF- $\alpha$ (a) and nitric oxide level (NO) (b) in serum samples of control, acute pancreatitis (AP), hemin pre-treated AP, hemin post-treated AP groups. Data represent the mean \pm S.E.M. $\mathrm{a}-\mathrm{p}<0.05-\mathrm{vs}$. control group; $\mathrm{b}-$ $\mathrm{p}<0.05$ vs. AP group; $\mathrm{c}-\mathrm{p}<0.05$ vs. hemin pre-treated AP group.

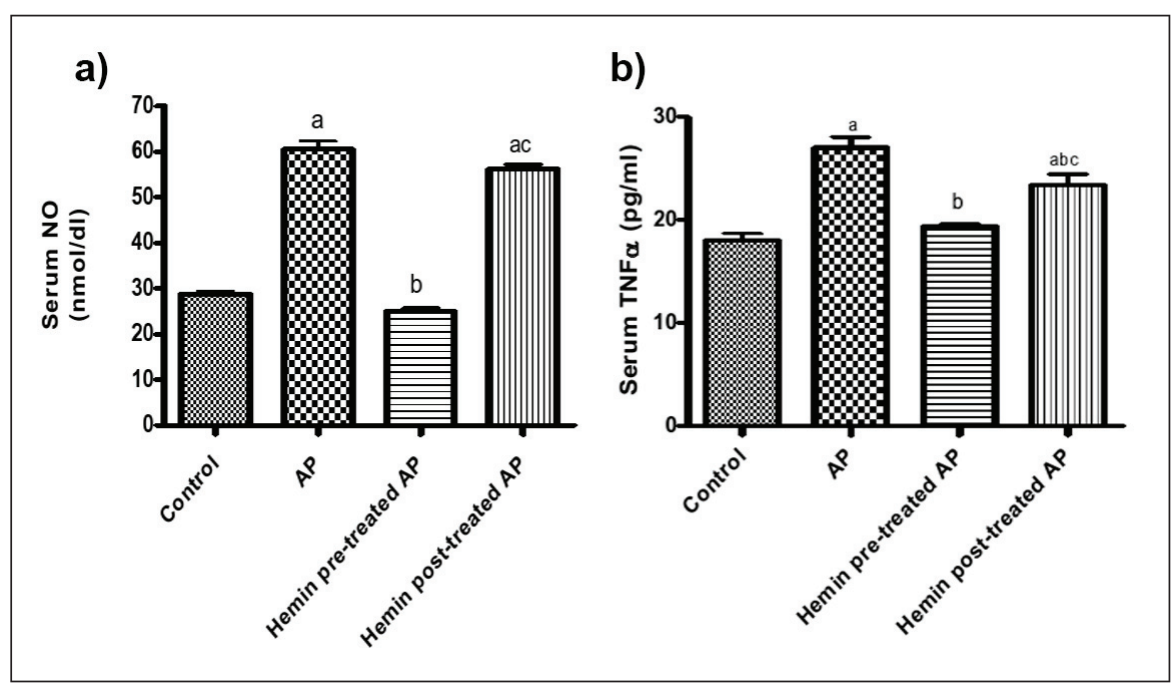


Table 2

Effect of pre- and post-hemin treatment on the oxidative status in the pancreatic and pulmonary tissues in L-arginine-induced acute pancreatitis

\begin{tabular}{lcccc}
\hline & Parameter & \multicolumn{2}{c}{ Pancreatic oxidative injury } & \multicolumn{2}{c}{ Pulmonary oxidative injury } \\
\cline { 2 - 5 } Group & $\begin{array}{c}\text { Pancreatic MDA } \\
(\mathbf{p g} / \mathbf{m g} \text { tissue })\end{array}$ & $\begin{array}{c}\text { Pancreatic TAC } \\
(\mu \mathrm{M} / \mathbf{m g} \text { tissue })\end{array}$ & $\begin{array}{c}\text { Pulmonary MDA } \\
(\mathbf{p g} / \mathbf{m g} \text { tissue })\end{array}$ & $\begin{array}{c}\text { Pulmonary TAC } \\
(\mu \mathrm{M} / \mathbf{m g} \text { tissue })\end{array}$ \\
\hline Control & $53.40 \pm 1.72$ & $83.60 \pm 1.03$ & $72.60 \pm 1.50$ & $74.20 \pm 1.56$ \\
AP & $153.20 \pm 1.59^{\mathrm{a}}$ & $22.20 \pm 0.86^{\mathrm{a}}$ & $226.80 \pm 2.47^{\mathrm{a}}$ & $46.20 \pm 0.86^{\mathrm{a}}$ \\
Hemin pre-treated AP & $57.20 \pm 1.06^{\mathrm{b}}$ & $80.20 \pm 0.5^{\mathrm{b}}$ & $76.60 \pm 1.21^{\mathrm{b}}$ & $70.40 \pm 0.50^{\mathrm{b}}$ \\
Hemin post-treated AP & $151.0 \pm 0.71^{\mathrm{ac}}$ & $25.40 \pm 0.92^{\mathrm{ac}}$ & $221.20 \pm 2.35^{\mathrm{ac}}$ & $42.80 \pm 0.58^{\mathrm{ac}}$ \\
\hline
\end{tabular}

Data are expressed as mean \pm S.E.M. of 6 rats in each group. ${ }^{a} \mathrm{p}<0.05$ vs. control group; ${ }^{b} \mathrm{p}<0.05$ vs. AP group; ${ }^{c} \mathrm{p}<0.05 \mathrm{vs.}$ hemin pre-treated AP group. AP - acute pancreatitis; MDA - malondialdehyde; TAC - total antioxidant capacities
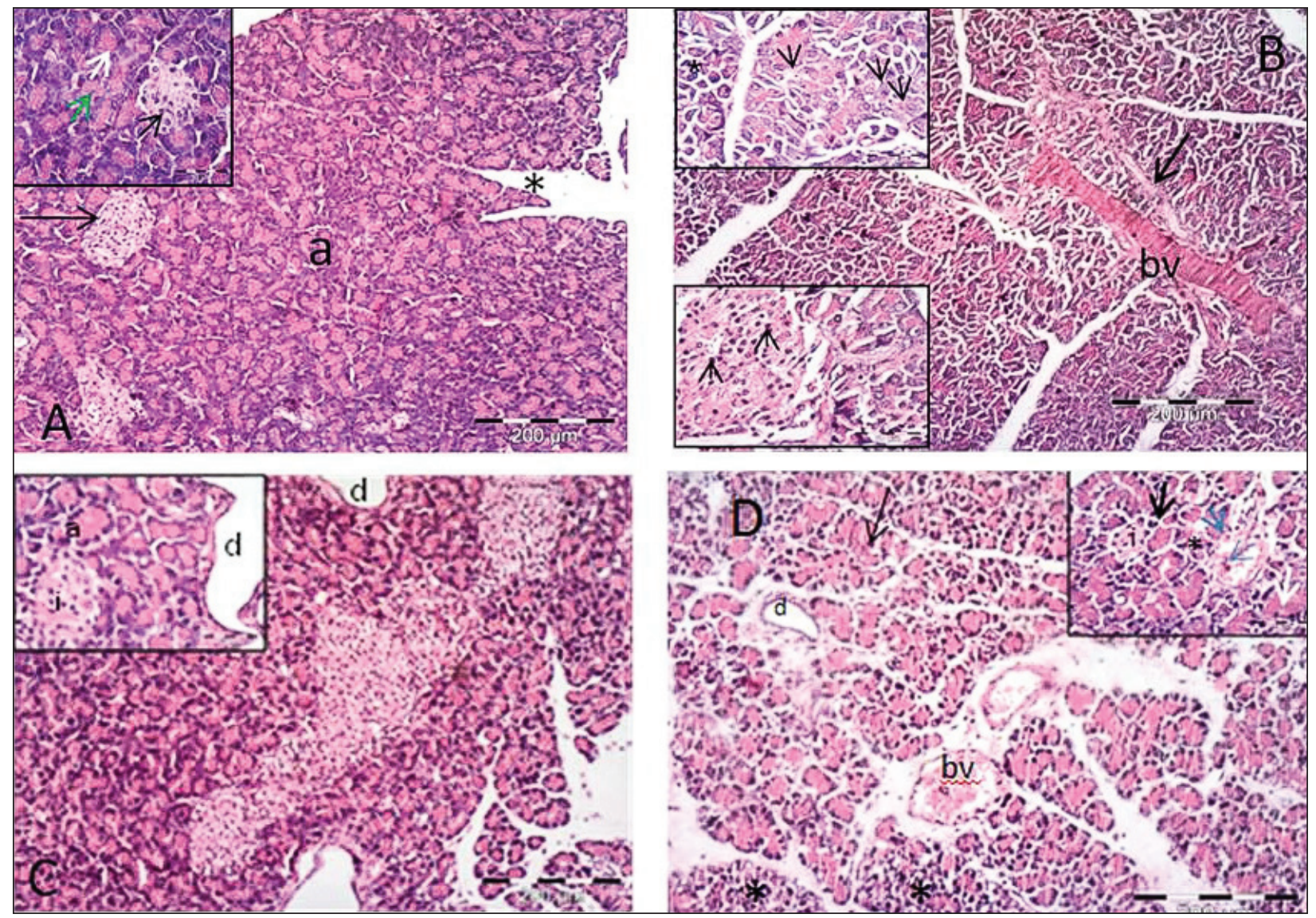

Figure 2. A photomicrograph of a section in the pancreas of (A) Control group showing pancreatic lobules containing acini (a), islets of langerhans (arrow) and unstained connective tissue $\left({ }^{*}\right)$ septa. X100. Inset is a higher magnification of normal pancreatic acini with basal basophilia, apical acidophilic granules (white arrow) and centroacinar cell (green arrow). Notice the presence of Islets of Langerhans (black arrow). X400. (B) AP group showing disruption of histoarchitecture, wide spaces between the lobules and the acini, wide dilated interlobular duct (arrow) and markedly congested blood vessel (bv). X100. Upper inset showing disorganized degenerated acinar cells. Many of them are vacuolated with absent apical acidophilia (black arrows). Others were shrunken and separated from their basement membrane $\left.{ }^{*}\right)$. Lower inset showing an islet of Langerhans with degenerated islet cells, some pyknotic nuclei (arrows). X400. (C) Hemin pre-treated group showing preserved pancreatic structure except for dilated duct (d). X100. Inset showing pancreatic acini resemble normal (a) and dilated intralobular duct with flattened epithelial lining (d). Notice islet of Langerhans (i). X400. (D) Hemin post-treated group showing wide spaces between the lobules, some lobules appear normal (black arrow). Others showing degenerated acini $\left({ }^{*}\right)$. Notice the congested blood vessel (bv) and the wide dilated duct (d). X100. Inset showing wide spaces between the acini (black arrow). Most of the acinia appear degenerated acini $(*)$, while few appear more or less normal (white arrow). Notice the congested blood vessel with marginated neutrophil (blue arrow) and the degenerated islet of Langerhans (i). X400 H\&E. 
Effect of either pre- or post-hemin treatment on the oxidative status in the pancreatic and pulmonary tissues in L-arginine-induced acute pancreatitis. Pancreatic and pulmonary levels of MDA were significantly higher while pancreatic and pulmonary levels of TAC were significantly lower in the AP group than that in the control group (Table 2). On the other hand, hemin pre-treatment significantly decreased the pancreatic and pulmonary MDA level and increased the pancreatic and pulmonary TAC levels as compared with AP group. However, hemin post-treatment failed to produce any significant difference in either MDA or TAC when compared with the AP group (Table 2).

Effect of hemin on histological findings in the pancreatic and pulmonary tissues. Sections of the control group showed the characteristic appearance of pancreatic acini with apical acidophilic granules and basal basophilia, and lightly stained islets of Langerhans (Figure 2A). The pancreatic tissue of the AP group showed that the normal histoarchitecture structure was markedly disrupted with wide spaces between the lobules and acini and the interlobular duct became markedly dilated. The blood capillaries were also dilated and congested. In addition, the aci- ni were markedly disorganized with many of the acinar cells became vacuolated with absent apical acidophilia, while the others were shrunken and detached from their basement membrane. The cells of the islet of Langerhans appeared degenerated and many cells had densely stained pyknotic nuclei (Figure 2B).

On the other hands, hemin pre-treated group, showed preserved normal pancreatic architecture, cells of the acini and of islets of Langerhans appeared more or less similar as in the control group but still many intralobular and interlobular ducts showed cystic dilation with flattening of the lining epithelia (Figure $2 \mathrm{C}$ ). However, in the post-treatment group with hemin wide spaces between the lobules and acini were still apparent. The acini within some lobules were normal while the others were degenerated, many congested blood vessel with marginated neutrophil were noticed in between the acini. Cells of the islet of Langerhans were still degenerated (Figure 2D).

Section in the lung of AP group showed marked alveolar wall thickening, many inflammatory cells invaded the bronchiolar wall, while their lumen became filled with red blood cells, hemosiderin granules, acidophilic substance and cellular debris as compared with the control group (Figure 3A, 3B1, 3B2). On the

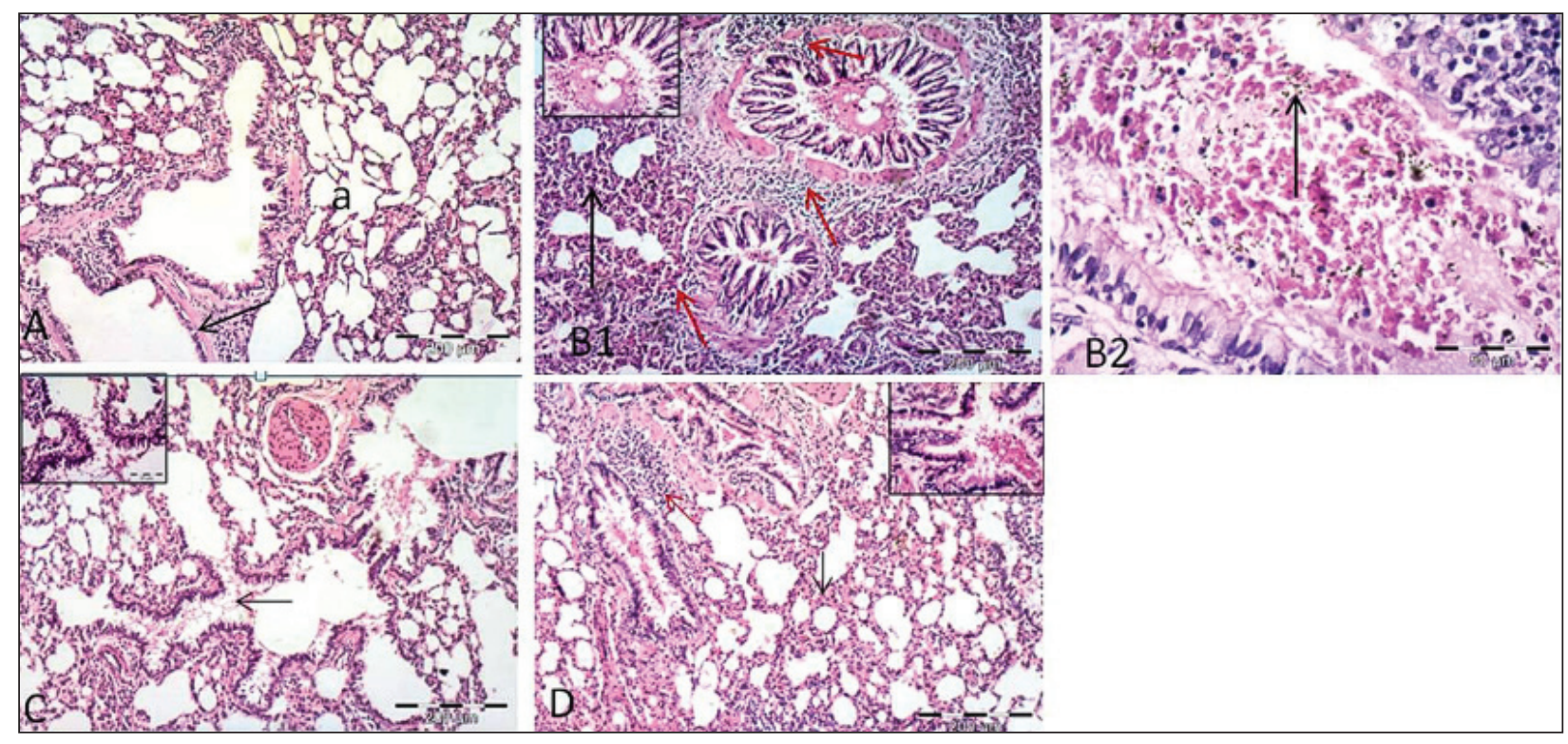

Figure 3. A photomicrograph of a section in the lung of (A) Control group showing expanded alveoli (A) separated by thin interalveolar septa. Many bronchioles can be recognized lined by ciliated columnar epithelium and with prominent circular smooth muscle in their wall (arrow). X100. (B1) AP group showing marked alveolar wall thickening (black arrow) and inflammatory cells invading bronchiolar wall (red arrows). X100. Inset showing of the bronchiolar lumen filled with acidophilic substance with many cellular depris. X400. (B2) Showing another bronchiolar lumen of the AP group flooded with red blood cells and haemosiderin granules (arrow). X400. (C) Hemin pre-treated group showing normal alveoli. Notice minimal acidophilic substance appears especially at the level of terminal and respiratory bronchioles (arrow). X100. Inset showing higher magnification of the bronchiolar lumen. X400. (D) Hemin post-treated group showing alveolar wall thickening (black arrow) and inflammatory cells invading bronchiolar wall (red arrows). X100. Inset showing bronchiolar lumen filled with acidophilic substance and cellular depris. X400 H\&E. 


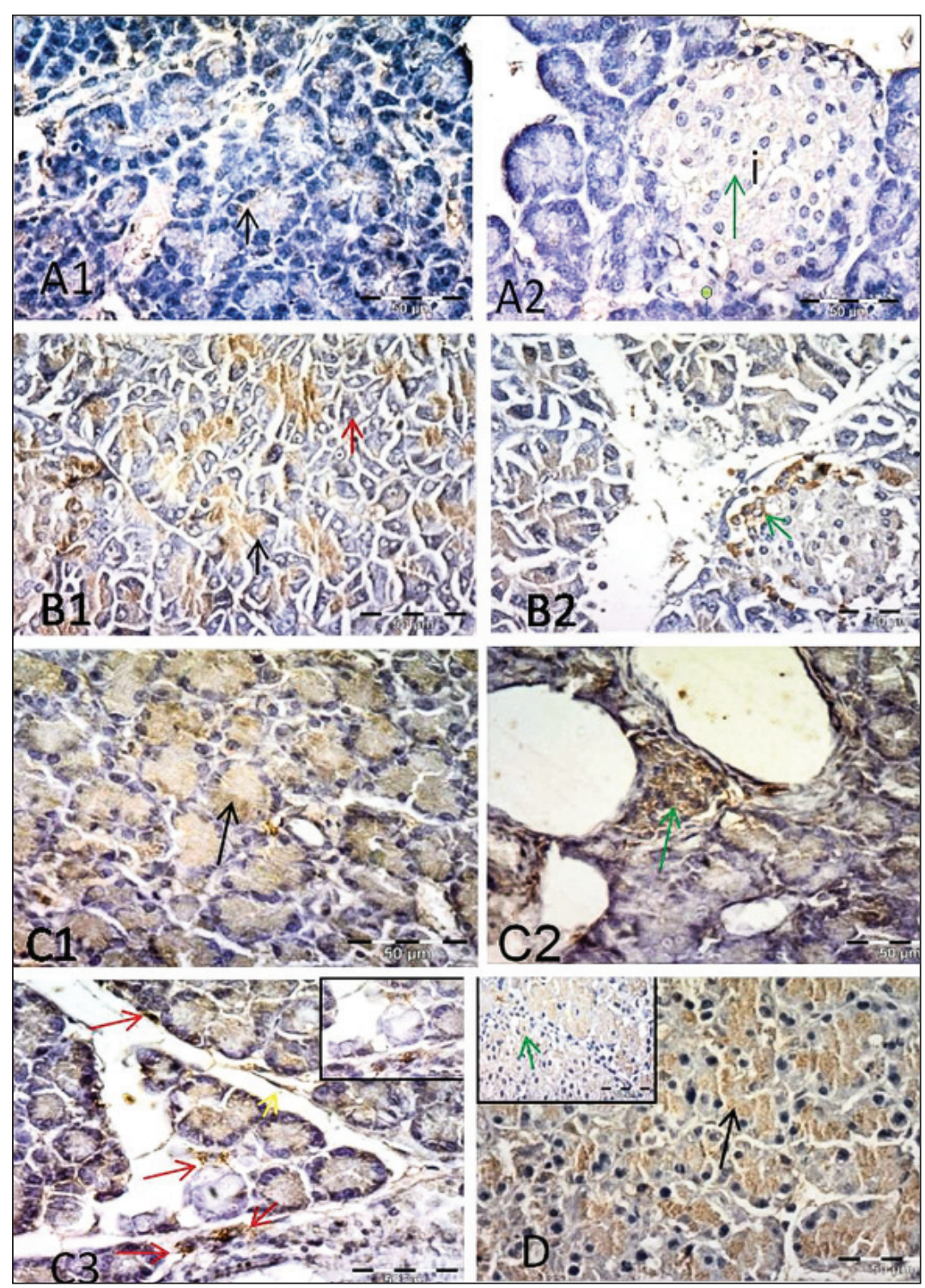

Figure 4. A photomicrograph of pancreatic section immunostained for HO-1 of (A1) and (A2) Control group showing faint staining in the cytoplasm of few acinar cells (arrow) and negative expression in the islet of Langerhans (i). X 400. (B1) and (B2) AP group showing some acinar cells with positive expression (black arrow), others with negative expression expression (red arrow). Few islet cells showing high expression (green arrow). X 400. (C1), (C2) and (C3) Hemin pre-treated group showing high cytoplasmic expression in the most of the acinar cells (black arrow) and in the cells of islet of Langerhans (green arrow). Notice the immune-positive macrophage like cells (red arrows) and fibrocyte like cell (yellow arrow). X 400 Inset is a higher magnification of immune-positive macrophage like cells. X 1000. (D) Hemin posttreated group showing cytoplasmic expression in the acinar cells (black arrow). Inset showing positive cells of the islet of Langerhans (green arrow). X 400.

other hand, the lung sections of hemin pre-treated group showed normal alveoli but still some acidophilic material was observed in the lumen of terminal and respiratory bronchioles (Figure 3C). However, lung sections of post-treated group with hemin had the same appearance of AP group except for less thickened alveolar wall (Figure 3D).
Effect of hemin on immunological findings in pancreatic tissues. The HO-1 immunohistochemical-stained sections of the control group showed faint cytoplasmic staining in scattered acinar cells with negative expression in the islet of Langerhans (Figure $4 \mathrm{~A} 1,4 \mathrm{~A} 2)$. In the AP group, positive expression was noticed in some acinar cells and in few cells of islet of Langerhans while others showed negative expression (Figure 4B1, 4B2). The HO-1 immunohistochemical-stained sections of hemin pre-treated group showed that most of the acini and islets of Langerhans revealed high cytoplasmic reaction. Many infiltrating macrophage like cells and fibrocyte like cell showed positive cytoplasmic reaction (Figure 4C1, 4C2, 4C3). In hemin post-treated group positive reaction was noticed in the acinar cells and in the islets of Langerhans (Figure 4D).

Morphometric results. The AP significantly increased the total histological scores of the pancreatic tissue as compared to the control group. However, pre-hemin treatment significantly lowered these scores but post-hemin treatment failed to produced any significant change as compared to the AP group (Table 3). Evaluation of histological signs of lung inflammation is summarized as follow (Table 4).

\section{Discussion}

Acute pancreatitis (AP) is an acute, non-bacterial inflammation of the pancreas. L-arginineinduced AP is a good-established model that induces pancreatitis with similar presentation to that in humans. L-arginine induces AP mechanisms including the conversion of $\mathrm{L}$-arginine to $\mathrm{NO}$ by nitric oxide synthase, causing oxidative stress in the pancreas in addition 
Table 3

Total histological scores of the pancreatic tissue

\begin{tabular}{|c|c|}
\hline Group $\quad$ Parameters & $\begin{array}{c}\text { Total histological scores } \\
\text { of pancreatic tissue }\end{array}$ \\
\hline Control & $0.80 \pm 0.37$ \\
\hline AP & $7.20 \pm 0.66^{\mathrm{a}}$ \\
\hline Hemin pre-treated AP & $2.00 \pm 0.70^{\mathrm{b}}$ \\
\hline Hemin post-treated AP & $4.60 \pm 0.36^{\mathrm{ac}}$ \\
\hline
\end{tabular}

Data are expressed as mean \pm S.E.M. of 6 rats in each group. ${ }^{a} \mathrm{p}<0.05$ vs. control group; ${ }^{b} \mathrm{p}<0.05$ vs. AP group; ${ }^{\mathrm{c}} \mathrm{p}<0.05$ vs. hemin pre-treated AP group. AP - acute pancreatitis

Table 4

Histological signs of the lung inflammation

\begin{tabular}{|c|c|c|}
\hline Group Parameters & $\begin{array}{c}\text { Alveolar wall } \\
\text { thickening }\end{array}$ & $\begin{array}{c}\text { Peri-bronchiolar } \\
\text { inflammation }\end{array}$ \\
\hline Control & - & - \\
\hline $\mathrm{AP}$ & ++++ & ++++ \\
\hline Hemin pre-treated AP & + & + \\
\hline Hemin post-treated AP & +++ & +++ \\
\hline
\end{tabular}

to endoplasmic reticulum stress. Moreover, L-arginine may also stimulate the induction of AP through increased production of cytokines, such as TNF- $\alpha$ and IL-6. The important of this model is that it is non-invasive and highly reproducible one (Elder et al. 2012). It is not only a good model to study the pathogenic mechanisms of acute necrotizing pancreatitis, but also tremendous to observe and influence time line changes of the disease. It also permits investigation of the associated organ damage (Park et al. 2014).

In the present study, administration of L-arginine significantly developed the AP characterized by elevated levels of serum amylase and lipase at $24 \mathrm{~h}$ with severe pancreatic and pulmonary histo-architectural changes. The serum levels of both enzymes have more sensitivity and specificity for the diagnosis of AP (Akyazi et al. 2013). Salem et al. (2014) have reported that this rise in amylase levels might possibly be due to the production of hydrolytic enzymes in AP that hydrolyzes phospholipids to liberate arachidonic acid and lysophospholipids and finally it has a cytotoxic function, leading to acinar cell necrosis. The destruction in the acinar cells resulted in increased the serum pancreatic enzymes, especially amylase and lipase levels.
The pathogenesis of AP is multifactorial. Autodigestion of the pancreas mediated by pancreatic enzymes has been considered the cause of changes in AP for more than one century. It has recently been demonstrated that intra-acinar trypsin activation (Pezzilli 2013) and the initiation of other pathway of pancreatitis, such as the cytokine cascade, are effective in understanding the AP pathogenesis (Yildar et al. 2015). Furthermore, TNF- $\alpha$ and IL-1 $\beta$ are especially prominent and are regarded as the "first-line" of cytokines (Akyazi et al. 2013). Yenicerioglu et al. (2013) have reported that following the intraperitoneal injection of L-arginine, IL-1 $\beta$, IL- 6 and TNF- $\alpha$, as noticed in our result, have been mentioned to be released from macrophages and monocytes, which are activated as a result of stimulation of peritoneal macrophages or severe damage to the pancreas.

Al-Malki (2015) has reported that cytokines are establish to induce an oxidative stress by the production of oxygen free radicals, inducible nitric oxide synthase (iNOS) expression, NO, which serve as a key cellular mediator of inflammation and superoxide production. In agreement with the data of other reports, (Biradar and Veeresh 2013; Xu et al. 2014), in the current study significant increase in the NO level was noticed in L-arginine received rats. In addition, Salem et al. (2014) have reported that the administration of excess L-arginine could induce iNOS activity and raise the $\mathrm{NO}$ level in pancreas. The raised levels of NO level can increase vascular permeability and may lead to a pancreatic edema and acinar cell damage.

In consistent with previous studies (Sowjanya et al. 2012), in the current study L-arginine induced models of AP significantly increased the pancreatic and pulmonary MDA and decreased TAC levels. MDA, an indicator of lipid peroxidation was elevated in L-arginine treated rats. Lipid peroxidation is a process mediated by free radicals, which results in an impairment of the membrane functional and structural integrity because of oxidative deterioration of polyunsaturated fatty acids of cell membrane. It could be attributed to the accumulation of free radicals proposed generated by L-arginine (Biradar and Veeresh 2013).

The mechanisms underlying ALI are still weakly understood. Evidence has been accumulating that cytokines and chemokines may play an important role in the respiratory pathogenesis. In addition, macrophages and in particular peritoneal macrophages, alveolar macrophages, and Kupffer cells, can also be activated during AP. Activated macrophages release systemic cytokines and inflammatory mediators that contribute to the systemic inflammatory response and to lung injury associated with AP. Another type 
of leukocytes that are involved in AP-associated ALI are neutrophils. Lung injury results from the local pulmonary endothelial cell injury resulted from the neutrophil-generated oxygen-radical products. Finally, pancreatitis-associated ALI is further related to specific effects on pancreatic enzymes like proteases and phospholipase $A_{2}$ (Wu et al. 2016).

The current study confirmed that hemin treatment when given before and not after L-arginine-induced AP significantly restored the serum amylase and lipase levels. Additionally, there were significantly decreased in the pancreatic and pulmonary MDA and increased in TAC. It indicates the protective effects of hemin on the acinar cells of pancreas. All these findings indicate that hemin has protective effects from pancreatitis and may improve the functions of pancreas. The reasons for that may be known to decrease the severity of L-arginine-induced AP. These data are in agreement with the findings of Nakamichi et al. (2005) who have demonstrated that pre-treatment, as a prophylactic, with hemin or hemin-activated cell protects against experimentally induced pancreatic injury.

Moreover, pre-hemin administration significantly decreased the histopathological scores of all pancreatic and pulmonary changes and reversed the elevation of TNF-a level in the treated group. Our results report that hemin attenuated the pancreatic and pulmonary tissues injury; this might be through inhibiting the release of inflammatory cytokines TNF-a. This inhibition could be because hemin increased the expression of HO-1 as observed in our study, which can show several potential protective mechanisms. Growing evidence suggests that HO-1 expression exerts anti-inflammatory activities by producing three anti-inflammatory metabolites (i.e. CO, ferrous iron as well as biliverdin) (Liu et al. 2015).

For example, HO-1-drived carbon monoxide (CO) decreases pro-inflammatory cytokine production, reduces apoptosis (Nikolic et al. 2014), improves organ function (Yao et al. 2015), and increases the survival (Wang et al. 2014). Biliverdin and bilirubin, the end bile pigments of heme degradation, protect the cells against hurt caused by oxidative stress in vitro (BenAmotz et al. 2014). Iron potentially acts as a catalyst of deleterious pro-oxidant reactions (Yegin et al. 2015).

Pancreatic HO-1 was up-regulated in the acinia and islet of Langerhans. Many immunopositive macrophage and fibrocyte like cells were noticed in the pre-hemin treated group. Earlier studies have reported that hemin up-regulates chemokines, particularly those that attract macrophages (Fortunato et al. 2006). The increase in HO-1 peritoneal and pancreatic macrophages in response to hemin raised the hypothesis that hemin administration induces redirection of peritoneal macrophages to the pancreas, which in turn are responsible for the observed protection afford by hemin (Nakamichi et al. 2005). Husseini et al. (2015) have found that short-term induction of HO-1 may promote a protective $\mathrm{M}_{2}$-like milieu in the pancreas and recruited mesenchymal cells, $M_{2}$ macrophages, and fibrocytes that imparted immunoregulatory and pro-repair effects. $\mathrm{M}_{2}$ and hemin activated macrophages in the pancreas are considered one of protective inflammatory cells (Huan et al. 2016). $M_{2}$ macrophage reduces inflammation and promote tissue repair. They have a distinctive ability to metabolize arginine to the "repair" molecule ornithine and by producing anti-inflammatory cytokines like IL-10 (Mills 2012).

Oxidative stress plays a vital role in the pathogenesis of AP and the beneficial effects of hemin might also be associated with suppression of neutrophilmediated MPO and lipoperoxidation, as demonstrated by reduced MDA level; events that reflect its antioxidant action (Collino et al. 2013). In addition, hemin inhibited the nuclear factor erythroid 2-related factor 2 (Nrf2) activating antioxidant response elements, which regulated genes for many antioxidant enzymes (Al-Kahtani et al. 2014).

Al-Kahtani et al. (2014) have also reported that hemin-mediated increase of HO-1 activity was proved enough to decrease the NO-dependent pathological and inflammatory conditions that support the obtained results in our study. Cross link exists between $\mathrm{HO}$ and NOS systems. It is obvious that the NO/NOS system induces $\mathrm{CO} / \mathrm{HO}$ system, while $\mathrm{CO} / \mathrm{HO}$ system reciprocately regulates the NO/NOS system via multiple mechanisms (Yadav and Greish 2011). Of note, $\mathrm{CO}$ suppresses the expression of iNOS protein by preventing the activation of nuclear factor-kappa $\mathrm{B}(\mathrm{NF}-\kappa \mathrm{B})$ which up-regulates the transcription of the iNOS gene (Taye and Ibrahim 2013).

Alternatively, the post-hemin administration did not demonstrate any protection against L-arginineinduced AP. This could be explained by the fact that hemin requires a preconditioning interval of several hours, which is mediated in part by induction of HO-1 to mediate its protective effect (Lu et al. 2014). In vivo, systemic pre-treatment with hemin was protective in multiple acute injury models, including brain (Zhang et al. 2008), heart (Hangaishi et al. 2000), kidney (Demirogullari et al. 2006), liver (Xue et al. 2007), and gut ischemia/reperfusion (Attuwaybi et al. 2004) and colitis (Zhong et al. 2010), and pancreatitis (Habtezion et al. 2011). Since hemin is not 
directly protective, but rather up-regulates an endogenous defense against oxidative stress and inflammation, its onset of action is possible to be delayed for several hours. It therefore may not be a best agent for treating rapidly progressing insults such as AP.

These results concerning the effects on the pancreas only are in the line with previous reports of Kambhampati et al. (2014) who have reported that panhematin if given before development of experimental pancreatitis can up-regulate hemin-activated macrophages and lead to less pancreatic injury and if given after the development of AP, can also decrease the extent of pancreatitis-related injury because panhematin induces rapid up-regulation of pancreatic HO- 1 within $2 \mathrm{~h}$ of dosing on contrary to the hemin which needs longer time up to 24 hours to increase HO-1 protein concentrations and activity. Increased $\mathrm{HO}-1$ protein synthesis and activity were continuous at 48 hours, perhaps in part because hemin is gradually released from albumin and then bound to hemopexin, a transport protein that has a higher affinity for hemin than albumin and transports hemin to the liver (Bharucha et al. 2010).

In conclusion, these results advise that hemin could effectively protect the rats against AP-associated lung injury when given before the induction of the pancreatitis but it did not demonstrate any improvement when is given after the induction. The hemin may inhibit excessive activation of alveolar macrophages from AP-associated lung injury through downregulation of generation of NO, TNF- $\alpha$ and MDA. These findings may indicate that pre-hemin administration is a suitable candidate as an effective strategy against AP-associated lung injury in high-risk patients, especially against post-ERCP (endoscopic retrograde cholangiopancreatography) acute pancreatitis through its anti-inflammatory and antioxidant effects. However, additional studies are necessary to verify these mechanisms. This study might also offer a basis for future investigations of the therapeutic role of other $\mathrm{HO}$ chemical or natural inducers in severe necrotizing pancreatitis.

\section{References}

Akbarshahi H, Sam A, Chen C, Rosendahl A, Andersson R. Early activation of pulmonary TGF- $\beta 1 /$ Smad2 signaling in mice with acute pancreatitis-associated acute lung injury. Mediators Inflamm 2014, 148029, 2014.

Akyazi I, Eraslan E, Gulcubuk A, Ekiz EE, Cirakli ZL, Haktanir D, Bala DA, Ozkurt M, Matur E, Ozcan M. Longterm aspirin pretreatment in the prevention of cerulein-induced acute pancreatitis in rats. World J Gastroenterol 19, 2894-2903, 2013.

Al-Kahtani M, Abdel-Moneim A, Elmenshawy O, El-Kersh M. Hemin attenuates cisplatin-induced acute renal injury in male rats. Oxid Med Cell Longev 2014, 476430, 2014.

Al-Malki A. Suppression of acute pancreatitis by L-lysine in mice BMC Complementary and Alternative Medicine. The official journal of the International Society for Complementary Medicine Research (ISCMR) 15, 193, 2015.

Attuwaybi B, Kozar R, Moore-Olufemi S, Sato N, Hassoun HT, Weisbrodt NW, Moore FA. Heme oxygenase-1 induction by hemin protects against gut ischemia/reperfusion injury. J Surg Res 2004, 53-57, 2004.

Ben-Amotz R, Bonagura J, Velayutham M, Hamlin R, Burns P, Adin C. Intraperitoneal bilirubin administration decreases infarct area in a rat coronary ischemia/reperfusion model. Front Physiol 5, 53, 2014.

Bharucha A, Kulkarni A, Choi K Camilleri M, Lempke M, Brunn GJ, Gibbons SJ, Zinsmeister AR, Farrugia G. Firstin-human study demonstrating pharmacological activation of heme oxygenase-1 in humans. Clin Pharmacol Ther 87, 187-190, 2010.

Biradar S, Veeresh B. Protective effect of lawsone on L-Arginine induced acute pancreatitis in rats. Indian J Exp Biol 51, 256-261, 2013.

Charavaryamath C, Keet T, Aulakh G, Townsend H, Singh B. Lung responses to secondary endotoxin challenge in rats exposed to pig barn air. J Occup Med Toxicol 3, 24, 2008.

Collino M, Pini A, Mugelli N, Mastroianni R, Bani D, Fantozzi R, Papucci L, Fazi M, Masini E. Beneficial effect of prolonged heme oxygenase 1 activation in a rat model of chronic heart failure. Dis Model Mech 6, 1012-1020, 2013.

Cote A, da Silva R, Cuello A. Current protocols for light microscopy immunocytochemistry. In: Cuello AC, editor. Immunohistochemistry II. Chichester: John Wiley and Sons, pp. 147-168, 1993.

Demirogullari B, Ekingen G, Guz G, Bukan N, Erdem O, Ozen IO, Memis L, Sert S. A comparative study of the effects of hemin and bilirubin on bilateral renal ischemia reperfusion injury. Nephron Exp Nephrol 103, e1-e5, 2006. 
Elder A, Saccone G, Dixon D. Lung injury in acute pancreatitis: mechanisms underlying augmented secondary injury. Pancreatology 12, 49-56, 2012.

Fortunato F, Deng X, Gates L, McClain CJ, Bimmler D, Graf R, Whitcomb DC. Pancreatic response to endotoxin after chronic alcohol exposure: switch from apoptosis to necrosis? Am J Physiol Gastrointest Liver Physiol 290, G232-G241, 2006.

Gulcubuk A1, Sonmez K, Gurel A, Altunatmaz K, Gurler N, Aydin S, Oksuz L, Uzun H, Guzel O. Pathologic alterations detected in acute pancreatitis induced by sodium taurocholate in rats and therapeutic effects of curcumin, ciprofloxacin and metronidazole combination. Pancreatology 5, 345-353, 2005.

Habtezion A, Kwan R, Akhtar E, Wanaski SP, Collins SD, Wong RJ, Stevenson DK, Butcher EC, Omary MB. Panhematin provides a therapeutic benefit in experimental pancreatitis. Gut 60, 671-679, 2011.

Hangaishi M, Ishizaka N, Aizawa T, Kurihara Y, Taguchi J, Nagai R, Kimura S, Ohno M. Induction of heme oxygenase-1 can act protectively against cardiac ischemia/reperfusion in vivo. Biochem Biophys Res Commun 279, 582-588, 2000.

Huan C, Kim D, Ou P, Alfonso A, Stanek A. Mechanisms of interleukin-22's beneficial effects in acute pancreatitis. World J Pathophysiol 7, 108-116, 2016.

Husseini M, Wang G, Patrick C, Crookshank JA, MacFarlane AJ, Noel JA, Strom A, Scott FW. Heme oxygenase-1 induction prevents autoimmune diabetes in association with pancreatic recruitment of M2-Like macrophages, mesenchymal cells, and fibrocytes. Endocrinology 156, 3937-3949, 2015.

Kambhampati S, Park W, Habtezion A. Pharmacologic therapy for acute pancreatitis. World J Gastroenterol 20, 16868-16880, 2014.

Lee E, Lee Y, Lee E, Ryu GR, Ko SH, Moon SD, Song KH, Ahn YB. Protective effect of heme oxygenase-1 on high glucose-induced pancreatic $\beta$-cell injury. Diabetes Metab J 35, 469-479, 2011.

Liu X, Wang X, Xin H, Wu D, Xin XM, Miao L, Zhang QY, Zhou Y, Liu Q, Zhang Q, Zhu YZ. Induction of heme oxygenase-1 by sodium 9-hydroxyltanshinone IIA sulfonate derivative contributes to inhibit LPS-mediated inflammatory response in macrophages. Cell Physiol Biochem 36, 1316-1330, 2015.

Lu X, Chen-Roetling J, Regan R. Systemic hemin therapy attenuates blood-brain barrier disruption after intracerebral hemorrhage. Neurobiol Dis 70, 245-251, 2014.

Mills C. M1 and M2 macrophages: Oracles of health and disease. Crit Rev Immunol 32, 463-488, 2012.

Nakamichi I, Habtezion A, Zhong B, Contag C, Butcher E, Omary M. Hemin-activated macrophages home to the pancreas and protect from acute pancreatitis via heme oxygenase-1 induction. J Clin Invest 115, 3007-3014, 2005.

Nikolic I, Saksida T, Mangano K, Vujicic M, Stojanovic I, Nicoletti F, Stosic-Grujicic S. Pharmacological application of carbon monoxide ameliorates islet-directed autoimmunity in mice via anti-inflammatory and anti-apoptotic effects. Diabetologia 57, 980-990, 2014.

Park J, Lee S, Chung M, Kwon SH, Kim EH, Ko KH, Kwon CI, Hahm KB. Antioxidative phytoceuticals to ameliorate pancreatitis in animal models: an answer from nature. World J Gastroenterol 20, 16570-16581, 2014.

Pezzilli R. Immunological aspects of acute respiratory distress syndrome in acute pancreatitis. Immunogastroenterology 2, 104-108, 2013.

Salem F, Lokman M, Kassab R. Ameliorative effects of watery extracts of boswella serrata and syzygium aromaticum on L-arginine induced acute pancreatitis in rats. World Journal of Pharmaceutical Research 3, 71-87, 2014.

Sowjanya J, Sandhya T, Veeresh B. Ameliorating Effect of Eugenol on L-arginine Induced Acute Pancreatitis and Associated Pulmonary Complications in Rats. Pharmacologia 3, 657-664, 2012.

Taye A, Ibrahim B. Activation of renal haeme oxygenase-1 alleviates gentamicin-induced acute nephrotoxicity in rats. J Pharm Pharmacol 65, 995-1004, 2013.

Wang X, Qin W, Qiu X, Cao J, Liu D, Sun B. A novel role of exogenous carbonmonoxide on protecting cardiac function and improving survival against sepsisvia mitochondrial energetic metabolism pathway. Int J Biol Sci 10, 777-788, 2014.

Wu D, Zeng Y, Fan Y. Reverse-migrated neutrophils regulated by JAM-C are involved in acute pancreatitis-associated lung injury. Sci Rep 6, 20545, 2016.

Xu X, Yang X, Bai Y, Zhao YR, Shi GS, Zhang JG, Zheng YH. Treatment with ginkgo biloba extract protects rats against acute pancreatitis-associated lung injury by modulating alveolar macrophage. Prz Gastroenterol 9, 43-48, 2014.

Xue H, Guo H, Li YC, Hao ZM. Heme oxygenase-1 induction by hemin protects liver cells from ischemia/reperfusion injury in cirrhotic rats. World J Gastroenterol 13, 5384-5390, 2007.

Yadav B, Greish K. Selective inhibition of hemeoxygenase-1 as a novel therapeutic target for anticancer treatment. J Nanomedic Nanotechnol S4, 005, 2011. 
Yao L, Wang P, Chen M, Liu Y, Zhou L, Fang X, Huang Z. Carbon monoxide-releasing molecules attenuate postresuscitation myocardial injury and protect cardiacmitochondrial function by reducing the production of mitochondrial reactive oxygen species in a rat model of cardiac arrest. J Cardiovasc Pharmacol Ther 20, 330-341, 2015.

Yegin Z, Iyidir O, Demirtas C, Suyani E, Yetkin I, Pasaoglu H, Ilhan C, Sucak GT. The interplay among iron metabolism, endothelium and inflammatory cascade in dysmetabolic disorders. J Endocrinol Invest 38, 333-338, 2015.

Yenicerioglu A, Cetinkaya Z, Girgin M, Ustundag B, Ozercan IH, Ayten R, Kanat BH. Effects of trimetazidine in acute pancreatitis induced by L-arginine. Can J Surg 56, 175-179, 2013.

Yildar M, Basbug M, Ozkan O, Cavdar F, Yaman I, Aksit H, Ozyigit MO, Aslan F, Derici H. The effects of 2-aminoethyl diphenylborinate on L-Arginine induced acute pancreatitis in the rats. Medical Science and Discovery 2, 352-357, 2015.

Zhang B, Wei X, Cui X, Kobayashi T, Li W. Effects of heme oxygenase 1 on brain edema and neurologic outcome after cardiopulmonary resuscitation in rats. Anesthesiology 109, 260-268, 2008.

Zhong W, Xia Z, Hinrichs D, Rosenbaum JT, Wegmann KW, Meyrowitz J, Zhang Z. Hemin exerts multiple protective mechanisms and attenuates dextran sulfate sodium-induced colitis. J Pediatr Gastroenterol Nutr 50, $132-139,2010$. 